\title{
Viewpoint in Garden Path Sentence: A Functional Approach
}

\author{
Yunfeng Shi, Yuhong Xie \\ College of International Studies, Southwest University, Chongqing, China \\ Email: shiyf@swu.edu.cn,xieyh@swu.edu.cn
}

How to cite this paper: Shi, Y. F., \& Xie, Y. H. (2017). Viewpoint in Garden Path Sentence: A Functional Approach. Open Journal of Modern Linguistics, 7, 33-40. https://doi.org/10.4236/ojml.2017.71003

Received: November 20, 2016

Accepted: February 5, 2017

Published: February 8, 2017

Copyright $\odot 2017$ by authors and Scientific Research Publishing Inc. This work is licensed under the Creative Commons Attribution International License (CC BY 4.0).

http://creativecommons.org/licenses/by/4.0/

\begin{abstract}
Garden path sentence is a kind of complex sentence which may cause structural and semantic ambiguity. Psycholinguistic analysis is the conventional approach to it. This paper will survey garden path sentence via viewpoint analysis within a systemic functional linguistic frame. In another word, garden path sentence will be discussed in term of lexicogrammar, clause complex, transitivity, theme and rheme, and cohesion and their relationship with viewpoint. It is expected that this approach will help to the interpretation and disambiguation of garden path sentences. Garden path effect attributes to polysemy of lexis, syntactic structure and sentence reader's viewpoint.
\end{abstract}

\section{Keywords}

Garden Path Sentence, Viewpoint, Clause Complex, Theme, Rheme, Ambiguity

\section{Introduction}

What leads us down the garden path in analyzing a sentence? We initially choose one interpretation by some experiences or habitual strategies. Reisberg (2010: p. 324) argues that people tend to assume that the sentences they hear or read are active rather than passive, and so they generally interpret a sentence's initial noun phrase as the "doer" of the action and not the recipient. As experience tells us, most of the sentences we encounter are active, not passive, and so this assumption is usually correct. However, this assumption may prove wrong whenever we do encounter a passive sentence. Garden path sentence is surveyed in some psycholinguistic works (Carroll, 2000). Harley (2001: p. 420) postulates that it is "a type of sentence where the syntactic structure leads you to expect a different conclusion from that which it actually has (e.g. 'the horse raced past the barn fell')". It is a kind of sentence in which the reader initially assumes a partic- 
ular meaning of a clause or sentence but discovers later that the assumption is incorrect, forcing him to backtrack and reinterpret the sentence. In other words, the reader has to form his viewpoint of judging whether he is reading a complete sentence or just reading a sentence fragment.

Dancygier and Sweetser (2012) argue that language and communication are considered, i.e. the content of linguistic expression is never independent of viewpoint. In analyzing garden path sentence, viewpoint may find its way in both its production and interpretation. The speaker consciously or unconsciously, deliberately or indeliberately, produces a garden path sentence either to express the kind of complex meaning or to challenge the hearer's ability to interpret and understand the given sentence. In the hearer's aspect, there is a kind of risk in his interpretation of the garden path sentence. He may apply his viewpoint and subjective experience to analyze the lexical units and syntactic structure of the sentence, and relate them to the possible relevant context, being linguistic, pragmatic, cognitive, or situational. He will achieve a sense of contentment if he succeeds in parsing and understanding this garden path sentence.

In a functional term, this kind of sentence can be taken as clause complex. Garden path sentence is the kind of sentences, which have ambiguous meaning both lexically and syntactically and therefore may lead the reader down to a garden path, i.e. a linguistically mistaken or incorrect understanding. Here are some examples of Garden path sentence:

1) The novice accepted the deal before he had a chance to check his finances, which put him in a state of conflict when he realized he had a straight flush (Foss \& Jenkins, 1973).

2) I was afraid of Ali's punch, especially since it had already laid out many tough men who had bragged they could handle that much alcohol (Clark \& Clark, 1977).

3) Since Jay always jogs a mile seems like a very short distance to him (Frazier \& Rayner, 1982).

4) The girl knows the answer to the physics problem was correct (Frazier \& Rayner, 1982).

The reason why these sentences get the name of garden path sentence is that while we are parsing the sentences, we get a subjective impression like following a garden path to a predicable destination until we are proved mistaken in our original interpretation and thus we are forced to backtrack and reinterpret them.

Garden path effect is not caused only by syntactic ambiguity in the sentences like "the horse raced past the barn fell", which are famous among psycholinguists. Lexical ambiguity can also cause garden path effect like "Ali's punch" in sentence 2). It seems these garden path sentences are rare, but in fact they are frequently used in natural discourse. Lexical ambiguity research has shown how readers or hearers determine the contextually appropriate meaning of a word with multiple senses. Lexical ambiguities pervade natural languages, with word exhibiting different types and degree of ambiguity. In the following sections garden path sentences will be analyzed from the perspective of viewpoint in 
terms of functional terms such as lexicogrammar, clause complex, transitivity, theme-rheme structure and cohesion.

\section{Lexicogrammar and Garden Path Sentence}

Even some simple sentences like "time flies like an arrow" may have ambiguous meaning if interpreted from special viewpoint ("time" as an imperative verb, "flies" referring to the disgusting insects). Garden path effect attributes to lexis and syntactic structure on the one hand, and to an unexpected meaning on the other. In other words, garden path sentence generally bring forth a structural surprise or a semantic surprise.

\subsection{Lexis and Garden Path Sentence}

Some garden path sentences can be understood with the help of a correct understanding of some key words in the sentences. These key words are mostly polysemous words. With the help of our encyclopedia knowledge, we know at least two different meanings of the word "deal". One is related to a business transaction, and the other, relevant in this case, pertains to the distribution of the cards to players in a card game. When reading a sentence, we tend to select the most appropriate meaning from our semantic knowledge of the language to comprehend the sentence and we have little or no conscious awareness of an alternative. We focus our attention on what we believe is relevant meaning of "deal" but failed to understand the sentence. As a result, we have to reread from the beginning of the sentence from another aspect of the meaning of "deal". There is another factor concerning what contributes to the garden path effect. It is the knowledge of semantic relationships among the words within the sentence, such as "deal", "finances" and "straight flush". The noun phrase "straight flush" refers to a hand of cards, all of one suit and in a continuous sequence in poker or card games, for example, the seven, eight, nine, ten, and jack of spades or hearts, or diamonds, or clubs.

There are two steps in understanding sentence 2). In this sentence, the key word is "punch", which means either a heavy boxing striking or the amount of alcoholic beverage. For most people they would come to a conclusion that "punch" means a boxing one (illustrated in step one) since they usually relate Ali to the world-known champion boxer and "Ali's punch" to "laid out many tough men". But as soon as they get to the last word "alcohol" they realize that is not the case and thus have to reread the sentence and eventually got the correct comprehension: "punch" in the sentence means "an amount of alcoholic beverage" (illustrated in step two). This two-step interpretation is illustrated in Figure 1.

\subsection{Garden Path Sentence as a Clause Complex}

Viewpoint plays a role not only in locating an appropriate layer of meaning, but in analyzing the clausal structure of a sentence, a complex one in particular. Syntactic ambiguity arises when a sequence of words has more than one syntactic 
Step one:

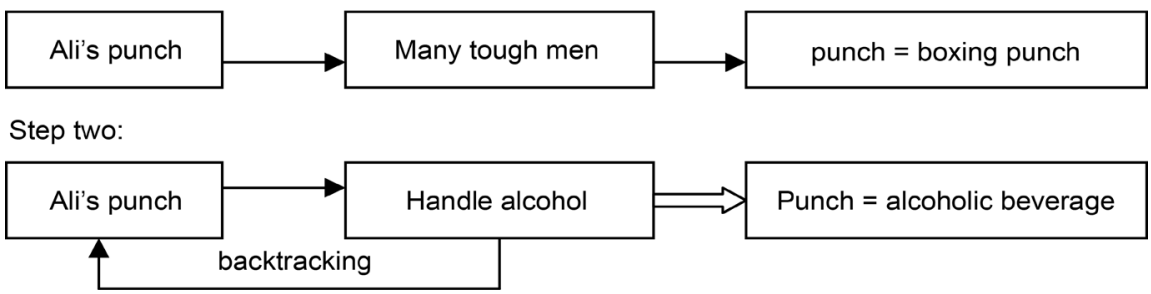

Figure 1. The two-step interpreting process of sentence 2).

interpretation. In functional grammar the term "group" is used because the unit is larger than word, i.e. "group of words" or "word group", evolved by expansion outwards from the word, is to be interpreted as word complex, which means a head word together with other words that modify it. In the same way, another larger unit, the sentence, can also be interpreted as a clause complex, which means a head clause together with other clauses that modify it. There is the same relationship between sentence and clause as there is between group and word. In other words, the sentence has evolved by expansion out wards from the clause.

However, the way in which the sentence is interpreted is somewhat different from that of the word. Not all of the sentence structure can be accounted for simply in term of Head + Modifier. There are various kinds of modifying, and also other similar relationships. In a sentence, the tendency is much more for any clause to have the potential for functioning with any value in a multi-clausal complex. Therefore, the notion of "clause complex' makes it possible to account in full for the functional organization of sentences. The relation between clauses can be interpreted in term of the "logical" component of the linguistic system. There are two systemic dimensions in the interpretation: one is the system of independency; the other is the logico-semantic system of expansion and projection. These two together will provide the functional framework for describing the clause complex.

Usually the pattern of clauses, garden path sentence in particular, is not as regular as this ideal one. The clauses may branch out at different places and are not all of the same kind. All logical structures in language are either paratactic or hypotactic. As a result, a typical clause complex is a mixture of paratactic and hypotactic sequences. The former is the relation between two like elements of equal status, one initiating and the other continuing; the latter is the relation between a dependent element and its dominant, the element on which it depends. This is mostly the case as far as garden path sentence is concerned. Take garden path sentence 1) for example. It is represented in Figure 2.

As is shown in Figure 2 that garden path sentence 1) is a hypotactic clause complex, which includes a group of clauses. In the sentence "the novice accepted the deal" is the dominant clause serving as the Head while the clauses following it serve as Modifiers. There are two modifiers of which modifier 1 is a finite temporal clause with a post modifier of the antecedent word "finance" and modifier 2 is a finite temporal clause with a mental process following "realized". The 
hearer has to change his viewpoint of parsing the structure and lexical meaning when he comes to the ending information. Only by doing this way can he find the correct meaning of this sentence.

\section{Garden Path Sentence and Transitivity}

According to Halliday (1994), transitivity involves participants, process, and environment. The choice of these elements in transitive system reflects the language users' viewpoint. The number and role of participants may vary from choosing only one participant functioning as the subject to choosing two functioning either as subject or complement. A speaker can choose one process or two or more to produce a simple, complex, or compound and complex sentence. The choice of circumstances may also reflect a viewpoint of time, place, or emotion.

Ideational function of language can be divided into two sub-functions: experiential and logical function. Logical function defines the clause complex, which has been discussed in the above part. The experiential function serves as a way of representing patterns of experience. Experience consists of a series of "goingson"-happening, doing, sensing, meaning and being and becoming, which are sorted out in the grammar of clause. Besides being a mode of action of giving and demanding good \&-services and information, the clause is also a mode of reflection, of imposing order on the endless variation and flow of events. This is achieved by the grammatical system - transitivity. The transitivity system construes the world of experience into a manageable set of process types, namely, six types of process: material, mental, relational, behavioral, verbal, and existential.

A process consists of three components: 1) the process itself; 2) participants in the process; and 3) circumstances associated with the process. Each component is realized by some groups and phrase classes. Functions of these groups and phrase class are expressed in the following Table 1.

\begin{tabular}{|l|l|l|l|l|}
\hline $\begin{array}{l}\text { The novice } \\
\text { accepted the deal }\end{array}$ & $\begin{array}{l}\text { before he had a chance } \\
\text { to check his finances }\end{array}$ & $\begin{array}{l}\text { which put him in a } \\
\text { state of conflict }\end{array}$ & $\begin{array}{l}\text { when he } \\
\text { realized }\end{array}$ & $\begin{array}{l}\text { he had a } \\
\text { straight flush }\end{array}$ \\
\hline \multirow{2}{*}{ Head } & \multicolumn{2}{|l|}{ Modifier } & \multicolumn{2}{|l|}{ mental process } \\
\hline & $\begin{array}{l}\text { Finite clause (by a } \\
\text { temporal conjunction) }\end{array}$ & post-modifier & \multicolumn{2}{|l|}{ temporal finite clause } \\
\cline { 2 - 3 } & Modifier 1 & Modifier 2 \\
\hline
\end{tabular}

Figure 2. Clausal analysis of sentence 1).

Table 1. Typical functions of group and phrase classes (Halliday, 1994).

\begin{tabular}{ll}
\hline Type of element & Typically realized by \\
\hline 1) process & verbal group \\
2) participant & nominal group \\
3) circumstance & adverbial or prepositional group \\
\hline
\end{tabular}


When reading this garden path sentence, we take for granted that "the girl knows the answer to the physics problem" is a correct interpretation. However, we find it incorrect to comprehend this way the time we read "was correct" and then are forced to reread the sentence and reinterpret it. According to Figure 3, "the girl" is the Senser in the cognition process of "knows", and all the other following part is Phenomenon. Interestingly, the phenomenon is a sentence of relational process, in which "the answer" serves as the Carrier, "was" an intensive process, and "correct" the attributive. Viewpoint is reflected in the choosing and positioning of participants, processes, and environments.

\section{Thematic Analysis of Garden Path Sentence}

A clause as a message structure consists of a Theme and a Rheme. ThemeRheme structure is a reflection of viewpoint, which can be considered either within or outside the clause. The theme is the element which served as the point of departure, or a starting point of the message, with which the clause is concerned. The Rheme is the remainder of the message, the part in which the theme is developed. It is also the focus of the sentence, or the ending point corresponding to the starting point. The theme is not necessarily a nominal group. It may also be an adverbial group or a prepositional phrase. Below the clause, both the verbal group and the nominal group incorporate the thematic principle into their own structure. Above the clause, the same principle lies behind the organization of paragraphs in written discourse. The "topic sentence" of a paragraph is nothing other than its theme. Garden path sentence is mostly in written form. The following Figure 4 is the thematic analysis of sentence 3 ).

Undoubtedly the comprehension of this sentence is of no exception with any

Sentence (4) will be analyzed in terms of one of these processes.

\begin{tabular}{|l|c|c|c|c|c|c}
\hline the girl & knows & the answer & to the physics problem & \multicolumn{2}{c|}{ was } & correct \\
\hline \multirow{2}{*}{ Senser } & $\begin{array}{l}\text { Process: } \\
\text { cognition }\end{array}$ & Carrier & (circumstances) & Process: intensive & Attributive \\
\cline { 3 - 6 } & \multicolumn{2}{l|}{ Phenomenon } \\
\hline
\end{tabular}

Figure 3. Mental process of sentence 4).

\begin{tabular}{|c|c|c|c|c|c|}
\hline since & Jay & always & jogs & a mile & $\begin{array}{l}\text { seems like a very short } \\
\text { distance to him }\end{array}$ \\
\hline structural & topical & model & & topical & \\
\hline textual & inte & ersonal & & interperso & \\
\hline \multicolumn{3}{|c|}{ Theme 1} & & \multicolumn{2}{|c|}{ Rheme 1} \\
\hline \multicolumn{2}{|c|}{ Theme 2} & Rheme & & Theme 3 & Rheme 3 \\
\hline
\end{tabular}

Figure 4. Thematic analysis of sentence 3). 
other garden path sentence, which needs a twice look at the sentence. In Figure, the thematic structure is analyzed in the two constituent clauses. Theme 1 is the clause "since Jay always jogs"; Theme 2 is within the clause "since" + (topical) "Jay" and Theme 3 is in the dominant clause (topical) "a mile". There the reader has to reread the sentence and correct the thematic structure in order to achieve a sound understanding of this garden path sentence.

\section{Cohesion and Garden Path Sentence}

Cohesion is the grammatical and/or lexical relationship between different elements of a text. This may be the relationship between different sentences and or between different parts of sentences. Cohesion is realized by various kinds of cohesive devices and ultimately aims to realize coherence, an ideal textural effect of verifying a logical interrelation within the sentence or text. Choices of cohesive devices may also reflect language users' viewpoint. According to Halliday (1994), there are four ways by which cohesion is created in English. They are reference, ellipsis, conjunction, and lexical organization. Choice of reference as a cohesive device shows the language user's viewpoint of seeing and handling the relationship between things or facts; it may be established at various distances and it usually serves to relate single elements that have a function within the clause. Ellipsis (including substitution) shows a relationship involving a particular form of wording, either a clause or some smaller item. It is often used in question-answer or adjacency pairs in dialogue. Conjunction is a way to establish the logical relations that characterize clause complexes in the absence of the structural relationship by which such complexes are defined. Lexical relation is realized by reiteration and collocation. This relationship is between either single lexical items or wordings lager than that. Many instances of cohesion usually involve more than one tie of different kinds in combining with one another.

1) The novice accepted the deal before he had a chance to check his finances, which put him in a state of conflict when he realized he had a straight flush (Foss \& Jenkins, 1973).

2) I was afraid of Ali's punch, especially since it had already laid out many tougher men who had bragged they could handle that much alcohol (Clark \& Clark, 1977).

Italicized words in sentences 1) and 2) serve as cohesive devices functioning coherence. In sentence 1), the two "the's" in "the novice accepted the deal" are non-specific demonstrative. "He, his, him" are anaphoric, all pointing to "the novice". "Before" and "when" are temporal conjunctions showing the speaker's temporal viewpoint. "Which" and "who" are used to modify the proceeding nominal group. "Deal", "finance", and "straight flush" in this sentence are all lexically related the card game. In sentence 2), "it" is anaphoric, referring to "Ali's punch" In sentence 2), "since" is causal-conditional enhancement to express the relationship between the clauses. The application of these cohesive devices demonstrates the language user's viewpoint in arranging and sequencing the meaning or information he intends to convey. 


\section{Conclusion}

In this paper garden path sentence has been analyzed from the perspectives of clause complex, transitivity, theme-rheme, and cohesion. Each perspective is closely related to the language users' viewpoint in that the language users' communicative purpose, linguistic preference may result in more or less subjective choices of linguistic units. Linguists comprehend garden path sentences by parsing them in a psycholinguistic approach. If they were analyzed in a functional way and took language users' viewpoint into consideration, it would be contributive to the interpretation and comprehension of garden path sentences.

Garden-path sentences highlight the fact that there's some risks attached to the strategy of interpreting a sentence as it arrives. That is because the information you need in order to interpret these sentences arrives only late in the sequence, and so, to avoid an interpretive dead end, you would be well advised to remain neutral about the sentence's meaning until you've gathered enough information.

Ambiguity or misunderstanding of garden path sentences may attribute primarily to the variety or multi-dimensionality of sentence structure and sentence meaning. From the perspective of speaker, or sentence producer, he may just as well make up garden path sentences consciously or unconsciously for the communicative purpose of achieving humorous effect or interesting effect by presenting challenging sentences in demand of understanding with reanalysis and effort. From the perspective of hearer, because his first understanding may come to a failure by being led to the wrong garden path, he is forced to have a second try to analyze the sentence and get back to the right garden path. Generally, success in understanding a deliberately presented complex sentence with kind of effort will bring interest, pleasure, or some sense of achievement to the hearer.

\section{References}

Carroll, D. W. (2000). Psychology of Language. Beijing: Foreign Language Teaching and Research Press.

Clark, H. H., \& Clark, E. V. (1977). Psychology and Language: An Introduction to Psycholinguistics. New York: Harcourt Brace Jovanovich.

Dancygier, B., \& Sweetser, E. (2012). Viewpoint in Language: A Multimodal Perspective. Cambridge: Cambridge University Press. https://doi.org/10.1017/CBO9781139084727

Foss, D. J., \& Jenkins, C. M. (1973). Some Effects of Context on the Comprehension of Ambiguous Sentences. Journal of Verbal Learning and Verbal Behavior, 12, 577-589. https://doi.org/10.1016/S0022-5371(73)80037-4

Frazier, L., \& Rayner, K. (1982). Making and Correcting Errors during Sentence Comprehension: Eye Movements in the Analysis of Structurally Ambiguous Sentences. Cognitive Psychology, 14, 178-210. https://doi.org/10.1016/0010-0285(82)90008-1

Halliday, M. A. K. (1994). An Introduction to Functional Grammar. London: Edward Arnold.

Harley, T. A. (2001). The Psychology of Language: From Data to Theory. Hove: Psychology Press Ltd. https://doi.org/10.4324/9780203345979

Reisberg, D. (2010). Cognition: Exploring the Science of the Mind (4th Edition). New York and London: W. W. Norton \& Company. 
Submit or recommend next manuscript to SCIRP and we will provide best service for you:

Accepting pre-submission inquiries through Email, Facebook, LinkedIn, Twitter, etc. A wide selection of journals (inclusive of 9 subjects, more than 200 journals)

Providing 24-hour high-quality service

User-friendly online submission system

Fair and swift peer-review system

Efficient typesetting and proofreading procedure

Display of the result of downloads and visits, as well as the number of cited articles Maximum dissemination of your research work

Submit your manuscript at: http://papersubmission.scirp.org/

Or contact ojml@scirp.org 